\title{
WestVirginiaUniversity
}

THE RESEARCH REPOSITORY @ WVU

Graduate Theses, Dissertations, and Problem Reports

2009

\section{Predictors of anticipated parenting efficacy in younger adults}

Danielle K. Tomczewski

West Virginia University

Follow this and additional works at: https://researchrepository.wvu.edu/etd

\section{Recommended Citation}

Tomczewski, Danielle K., "Predictors of anticipated parenting efficacy in younger adults" (2009). Graduate Theses, Dissertations, and Problem Reports. 2786.

https://researchrepository.wvu.edu/etd/2786

This Thesis is protected by copyright and/or related rights. It has been brought to you by the The Research Repository @ WVU with permission from the rights-holder(s). You are free to use this Thesis in any way that is permitted by the copyright and related rights legislation that applies to your use. For other uses you must obtain permission from the rights-holder(s) directly, unless additional rights are indicated by a Creative Commons license in the record and/ or on the work itself. This Thesis has been accepted for inclusion in WVU Graduate Theses, Dissertations, and Problem Reports collection by an authorized administrator of The Research Repository @ WVU. For more information, please contact researchrepository@mail.wvu.edu. 
Predictors of Anticipated Parenting Efficacy in Younger Adults

Danielle K. Tomczewski, B.A.

Thesis submitted to the Eberly College of Arts and Sciences

at West Virginia University

in partial fulfillment of the requirements

for the degree of

Master of Science
In
Psychology

Julie Hicks Patrick, Ph.D., Chair

Katherine Karraker, Ph.D.

Steven Branstetter, Ph.D.

Department of Psychology

Morgantown, West Virginia

2009

Keywords: anticipated parenting efficacy, sex, younger adults

Copyright 2009 Danielle K. Tomczewski 


\begin{abstract}
Predictors of Anticipated Parenting Efficacy in Younger Adults
\end{abstract}

\title{
Danielle K. Tomczewski
}

Prior research has indicated that anticipated parenting efficacy, the degree to which individuals perceive that they will be an effective parent, predicts their later parenting competency (Coleman et. al., 2002; Teti \& Gelfand, 1991). Although additional correlates of parenting efficacy have been identified, such as knowledge of childhood development (Conrad, Gross, Fogg, \& Ruchala, 1992) and prior contact with children (Coleman \& Karraker, 2000; Williams et al., 1987), little research has examined the predictors of anticipated parenting efficacy. The current study examined anticipated parenting efficacy in a sample of 481 younger adults. Participants completed self-administered on-line surveys related to their biological sex, knowledge of childhood development, prior contact with children, affinity for children, and their masculinity and femininity.

Results of a hierarchical linear regression showed that by itself, biological sex was a unique predictor of anticipated parenting efficacy $\left(F(1,478)=4.01, p<.05 ;\left(R^{2}=.01\right), \beta=-.52\right)$. However, when knowledge, contact, affinity, femininity and masculinity were entered in subsequent steps, the effects of biological sex were significantly reduced $F(3,473)=12.30, p<$ $.001,(\beta \operatorname{sex}=-.25, p>.05)$. These results indicate that sex differences in anticipated parenting efficacy can be better understood by examining other correlates with sex, such as affinity for children and gender roles. 
Parenting Efficacy iii

Table of Contents

Introduction

Method

Results

Discussion

References

Figures

Curriculum Vita 


\section{Introduction}

Individuals' perceptions of their parenting efficacy are of interest to researchers because these perceptions are closely tied with parental and child outcomes. For example, those who report higher parenting efficacy are less likely to report feelings of depression and behavior problems with their children, more likely to report feelings of parental satisfaction, less likely to report feeling stressed (Coleman et. al., 2002), and are less likely to make negative internal attributions about their children or employ coercive discipline tactics (Bondy \& Mash, 1999).

In addition to assessing the competency of parents, it is important to study the concept of "anticipated parenting efficacy." To differentiate, anticipated parenting efficacy is one's estimation of how competent he or she will be at parenting before actually becoming a parent; parenting efficacy is the self-report of how competent a parent views themselves to be regarding the performance of various parenting duties (Coleman et. al. 2002). The two are correlated, as perceptions of anticipated parenting efficacy do positively correspond with reported post-natal parenting efficacy, and post-natal parenting efficacy is in turn related to actual parenting competence and performance (Coleman et. al., 2002; Teti \& Gelfand, 1991). That is, people who expect to be competent parents often perform better in actual parenting tasks than those who predict that they will be less competent parents.

Higher reported parenting efficacy has been found to be predictive of higher parenting quality. In the development of their Maternal Efficacy Questionnaire, Teti and Gelfand (1991) found that maternal self-efficacy accounted for $21 \%$ of the variance in maternal competency scores. When maternal self-efficacy was entered into a hierarchical regression equation predicting parenting competency, maternal self-efficacy uniquely accounted for an additional 5\% (Total $\left.R^{2}=.60\right)$ of the variance above and beyond that accounted for by maternal education, 
family income, infant age, marital status, maternal depression, infant difficulty, and socialmarital supports (Teti \& Gelfand).

Although many researchers have examined the correlates of parenting efficacy, this line of research has not been extended to anticipated parenting efficacy. It is important to focus specifically on anticipated parenting efficacy, because developing methods of preventing poor parenting practices saves time and money, and younger adults are provided with valuable practical parenting tips. One of the ways to identify correlates of anticipated parenting efficacy is to investigate whether or not known correlates of parenting efficacy also apply to anticipated parenting efficacy.

\section{Theory}

Research on anticipated parenting efficacy is guided by Bandura's Self-Efficacy Theory (Bandura, 1989). According to this aspect of Social Cognitive Theory, one of the central determinants of people's actions is their belief in their own ability to control and change their behavior, termed "self-efficacy." Bandura (1989) proposed that individuals' actions, affective states, and motivation to complete a task are based on their perception of their ability to succeed rather than on their true ability. This estimation of one's own efficacy is a reliable predictor of successful task performance (Bandura). According to his theory, if an individual believes he or she can perform a task, he or she will be more likely to persevere in the face of adversity, have higher motivation, set higher goals, remained more focused on the task, visualize himself or herself as succeeding, and actually be more likely to perform well than someone with lower selfefficacy (Bandura). 
Self-efficacy is both general and domain-specific. Individuals may have a high trait-like general sense of self-efficacy, similar to optimism, and therefore be likely to have slightly higher efficacy in many domains (a feeling that they can conquer most challenges; Bandura, 1989). However, self-efficacy is also domain-specific, and implies knowledge of appropriate responses to a specific task or challenge, based on previous experience in successfully dealing with similar situations (Bandura). Domain-specific self-efficacy can be cultivated through either increasing knowledge of the task, or through more experience at the task (Bandura).

This concept of increasing efficacy through increased familiarity or experience is similar to Erikson's theory regarding "trying on roles," in which adolescents and young adults seek to develop their sense of self by envisioning their lives with different roles (such as that of a parent; Erikson, 1959). Researchers are now perceiving that the period of "emerging adulthood" extends the time frame for the onset of the adult role by several years or in some cases decades beyond the teenage years (Arnett, 2000). Therefore, it may be that many college students and other younger adults today are still in the process of developing their identity and honing their role expectations. Thus, anticipated parenting competency may be one way that emerging adults engage in Erikson's identity and role development.

In relating Bandura's and Erikson's theories to parenting, it follows that individuals who expect to become competent parents will be more likely to practice competent parenting behaviors upon having children than individuals who report low confidence in their parenting abilities. In addition, it may be those individuals with knowledge of appropriate behavior and previous experience in similar situations that will be more likely to have higher anticipated parenting efficacy. It is therefore important to identify which factors predict anticipated parenting efficacy in younger adults, as it is these individuals who are still trying on roles, and 
developing their identity. Thus, they may be open to interventions and change.

\section{Contact with Children}

One variable that has been linked with parenting efficacy is frequency of contact (experience) with children. This research is also guided by Bandura's Self-Efficacy Theory, and in accordance with this theory, mothers who have had prior experience with children and infants other than their own are more likely to view themselves as being competent at parenting tasks.

Although the link between prior experience with children and increased parenting efficacy seems self-evident, research into this connection has been sparse. In a rare longitudinal study, Williams et. al. (1987) collected data from 238 pregnant mothers and followed them until their children were 2 years old. The purpose of the study was to record and assess the development of the bond and attachment between mothers and their children. As part of the

study, researchers measured experience with infants, which was operationalized as the amount of contact mothers had with infants other than their own, and assessed before the birth of their current child. Results showed that such contact was a significant predictor of higher quality attachment relationships between the infants and their mothers $\left[F(2,153)=16.29, p<.0001 ; \mathrm{R}^{2}\right.$ $=.18)]$. In addition, mothers who expressed more confidence were more likely to have securely attached relationships with their infants, indicating a higher quality parent-child relationship (Williams et. al., 1987).

Similarly, Coleman and Karraker (2000) assessed the relations among both general and parenting-specific self-efficacy, maternal and child characteristics, and parental satisfaction among 145 mothers whose children ranged from 5-12 years old. Measures used were the SelfEfficacy Scale (S-ES) (to assess general self-efficacy), and the Self-Efficacy for Parenting Tasks 
Index (SEPTI), Parenting Sense of Competence Scale (PSOC), and Parenting Self-Agency (PSA) (to assess parenting efficacy). Results indicated that mothers who were more experienced with children other than their own (as compared to less experienced mothers) reported more selfefficacy in parenting their own children $(r=.23$ for domain-general self-efficacy, and $r=.32$ for domain-specific self-efficacy) (Coleman \& Karraker, 2000). Experience was assessed by asking mothers to rate their past experience with children other than their own by choosing "none," "very little," "moderate amount," or "very much." The following study will seek to replicate and expand the work of Williams et. al. and Coleman and Karraker by examining the effects on parenting efficacy of different types of prior experience with children.

\section{Knowledge of Child Development}

In addition to previous experience with children, knowledge of typical childhood development is also related to higher parenting efficacy (Coleman et. al., 2002). A lack of knowledge of appropriate developmental milestones often leads to overly-high or overly-low expectations for one's own child's development. This, in turn, can lead to negative outcomes for both the parents and child (Karraker \& Evans, 1996). Expectations which are too high have been linked to parental frustration, and punitive and restricting behavior towards the infant, as well as a tendency towards child abuse (Schilmoeller \& Baranowski, 1985; Twentyman \& Plotkin, 1982). Unrealistically low expectations, on the other hand, are correlated with the parental belief that the infant is helpless, the tendency to under-stimulate the infant, and slower infant growth (Schilmoeller \& Baranowski; Twentyman \& Plotkin, 1982).

One study investigating the impact of parental knowledge of infant development on parenting outcomes is that by Conrad, Gross, Fogg, and Ruchala (1992). The purpose of this 
study was to assess the effect of maternal confidence and knowledge of child development on mother-child interactions. In this study, 50 mother/toddler dyads were recruited, in which each mother was married and 21 years of age or older $(M$ age $=30.7 \mathrm{yr}, S D=4.8 \mathrm{yr})$, and the toddlers were between 12 and 36 months old $(M$ age $=22.2 \mathrm{mo}, S D=6.8 \mathrm{mo})$. Mothers were tested on their knowledge of childhood development using the Knowledge of Infant Development Inventory (KIDI), and their interactions with their toddlers were videotaped and coded for quality of mother-child interaction. Conrad et al. found an interaction between maternal confidence and knowledge of development on quality of mother-child interactions $(F(2,49)=$ $3.55, p<.05)$. Specifically, they found that mothers who were the most confident and knowledgeable had more positive interactions than those who reported a high degree of confidence, yet were less knowledgeable about childhood development. These results indicate that knowledge of childhood development contributes to parenting efficacy.

Further support for the link between knowledge and parenting efficacy was found through the longitudinal study by Benasich and Brooks-Gunn (1996). Researchers in this study interviewed 985 mothers of low-birth weight, premature infants, starting from the time of their infant's birth until their children were 36 months in age. The study was designed to assess the relationship between maternal knowledge of child development and concepts of child rearing with child cognitive and behavioral outcomes, as well as home environment. Knowledge of child development in this study was also assessed by the Knowledge of Infant Development Inventory (KIDI). They found that mothers' knowledge of the developmental milestones of childhood (for example, at what age children typically begin to sit, walk, and talk), predicted higher outcomes for their children on the Achenbach Child Behavior Checklist (36 months, $r=$ $.22)$, the Bayley Scales of Infant Development (24 months, $r=.40)$, and the Stanford-Binet 
Intelligence Scale (36 months, $r=.44)$ (Benasich \& Brooks-Gunn, 1996). These results lend support to the idea that mothers who are well-informed about infant development are less likely to have unrealistic expectations for their children, and more likely to raise intelligent, healthy, and well-adjusted offspring.

\section{Biological sex}

Although much of the extant literature has examined perceptions of parental efficacy among women, few studies have attempted to examine these associations among men. This may indicate an unspoken stereotype of our culture, that parenting is more central to the development of women than men. This neglect of men is unfortunate, because fathers are a significant contributor to the lives of their children. For example, studies have shown that infants develop secure attachments with their fathers as well as their mothers, preferring either parent over unfamiliar adults in strange situations (Lamb, 1997, 2002). Fathers are not merely substitute mothers, however, and provide their own unique contributions to the parent-infant relationship. Fathers are more likely than mothers to engage in active play with their children, and children (especially boys) are more likely to seek out their fathers for playful interactions (Lamb, 1997, 2002). In addition, children with secure attachments to their fathers are more likely to have higher quality friendships with other children (Zimmerman, 2004), and to perform better socially and academically (Flouri, 2005).

This study seeks to examine and explain the contribution of biological sex to anticipated parenting efficacy, to see if women truly are more efficacious parents than men, as a result of their biology, or if there are unique patterns of behavior that better explain the relationship. In this way, rather than feeding the stereotype that women are better parents, this study seeks to 
identify attributes which can be strengthened in either gender, such as one's masculinity or femininity levels, in order to make individuals more efficacious parents regardless of biological sex.

\section{Statement of the Problem}

Anticipated parenting efficacy has been shown to be correlated with later efficacy as a parent (Raver \& Leadbeater, 1999; Teti \& Gelfand, 1991; Williams et al., 1987). This relates to Bandura's Self-Efficacy Theory and Erikson's Psychosocial development theory regarding the trying on of roles (Bandura, 1989, Erikson, 1959). Previous studies have found links between knowledge of child development and experience with children and higher parenting efficacy. However, little research has examined the correlates of anticipated parenting efficacy. This is an important avenue of research, because successful identification of the predictors of poor anticipated parenting efficacy can be used to guide interventions designed to improve actual parenting efficacy, ideally before these individuals become parents.

\section{Hypotheses}

Based on the research cited above, the hypotheses for this study are as follows:

1. Contact with children and infants will be positively associated with anticipated parenting efficacy (Coleman \& Karraker, 2000; Williams et al., 1987), such that more frequent contact will be associated with higher anticipated parenting efficacy.

2. Knowledge of infant and child developmental milestones will also be positively associated with anticipated parenting efficacy (Benasich \& Brooks-Gunn, 1996; Gross, 
Fogg, \& Ruchala, 1992), such that more knowledgeable participants will report higher anticipated parenting efficacy.

3. Exploratory analyses will also be conducted to test the assumption that higher liking (affinity) for children will result in higher anticipated parenting efficacy.

4. Given that fathers provide their own unique contributions in their children's lives, the present study examines biological sex as a predictor of anticipated parenting efficacy, a relationship which has not yet been tested in the literature. It is hypothesized, however, that as biological sex is only a proxy variable, any differences in anticipated parenting efficacy found will be lessened in the prescence of masculinity and femininity levels. Little research has addressed biological sex differences in anticipated parenting efficacy. Therefore, mean scores on our anticipated parenting efficacy measure will be compared across biological sex. If differences emerge, biological sex will be entered first in all subsequent regression analyses.

5. Based on the results of the exploratory biological sex analyses, an additional hypothesis is tested. Because biological sex is often a proxy for other causal factors, this study will examine its relationship to masculinity and femininity, personal dispositional factors that might influence parenting behaviors. Masculinity and femininity scores will be entered into a hierarchical regression of parenting efficacy scores, following biological sex. Thus, all five independent variables (contact with children, knowledge of developmental milestones, biological sex, masculinity, and femininity) will account for a significant amount of the variance in anticipated parenting efficacy scores. 
Method

Design

This study employed a cross-sectional design, in which the dependent variable was anticipated parenting efficacy, and the independent variables were knowledge of child development, biological sex, and masculinity and femininity levels. Age was held constant across the analyses.

\section{Participants and Procedures}

The proposed study utilized data from a larger completed project, with data collected from late August to the end of September, 2006, from undergraduate students enrolled in Psychology 241: Introduction to Human Development, at West Virginia University. In accordance with IRB protocol, consent was collected. Participants included 319 females, and 162 males, with an age range of $17-55$ (Mean age $=19.92, S D=2.37$ ). In keeping with the characteristics of the region, most participants (94.3\%) were Caucasian. In addition, 98.0\% were unmarried and $94.6 \%$ did not have children. Only those who reported not yet having children were included in the analyses.

\section{Measures}

Anticipated Parental Efficacy Questionnaire

To index anticipated parental efficacy, an adaptation of Teti and Gelfand's (1991) Maternal Efficacy Questionnaire (MEQ) was used. Although designed for mothers, the MEQ has been successfully used with parents of both sexes (Coleman \& Karraker, 2003.) The MEQ is a 
10-item scale that assesses how competent the individual feels when faced with various tasks of child-rearing, such as understanding their child's needs and desires, communicating their wishes to the child, and comforting the child when he or she is distressed. For example, participants are asked, "When your baby is upset, fussy, or crying, how good are you at soothing him or her? (Not good at all, Not good enough, Good enough or Very good)." This scale has also been reported to have "strong concurrent validity" with the Parenting Stress Index's Sense of Competence subscale (Abidin, 1990, as cited in Coleman \& Karraker, 2003). It was modified for the present study by changing the tense of the questions from the present to the future tense. In the current sample, a mean of $33.73(S D=3.28)$ was obtained. However, internal consistency was low, with Cronbach's alpha equal to .78.

\section{Contact with Children}

Contact with children was assessed by three questions. These questions asked the frequency of contact in the past year (At least once a week, At least once a month, Rarely (less than 1 time/month) or Not at All) with infants, preschoolers, and younger children. Items were scored such that higher scores reflected more frequent contact. These items were summed to create a scale. The scale mean was $8.74(S D=2.17$; Cronbach's alpha $=.76)$.

\section{Knowledge of Infant and Child Development}

Participants completed Field's (1981) Developmental Milestones Survey to assess their knowledge of typical development in infancy and childhood. Questions in this 8-item scale ask at what age an infant or child should first be able to accomplish a developmental milestone (Ex: "At what age should a baby be able to crawl?"). Responses were recorded in months. In accordance with methods used by Karraker and Evans (1996), participants' responses were 
scored as correct if they fell within 2 months of the correct answer, and incorrect if they fell beyond that range. The number of correct responses was tallied to form an accuracy scale, with a mean of $4.33(S D=1.77$; Kuder-Richardson $=.51)$. This low internal consistency score indicates that this scale may not be uni-dimensional.

Bem Sex-Role Inventory

Sex roles, perceived behavioral norms that are typical of either males or females, are a pervasive part of individuals' personality and behavioral schemas. These roles are subject to wide variation as a result of factors like culture, ethnicity, age, and historical cohort (Bem, 1974). In an attempt to explore which factors composed the masculine and feminine sex roles, and also to show that individuals were more androgynous than originally hypothesized, Bem created Bem Sex-Role Inventory (BSRI) in 1974. The BSRI is composed of 60 adjectives, which are divided into a masculine, feminine, and neutral (or androgynous) scale. During the administration of the BSRI, participants are asked to rate themselves on each of the items using a 7-point likert scale from "Never or Almost Never" (1) to "Always or Almost Always True" (7). In a recent re-validation study, internal consistency of the Masculinity and Femininity scales exceeded .90 (Holt \& Ellis, 1998). The Cronbach's alpha for the BSRI in the current sample is .82 for femininity, and .84 for masculinity. The sample means were 98.95 for the femininity subscale, and 96.98 for the masculinity subscale. 


\section{Results}

\section{Preliminary Analyses and Descriptive Statistics}

Prior to hypothesis testing, independent samples t-tests comparing men and women on all of the study variables were conducted. As shown in Table 1, when using pairwise deletion, men and women differed significantly on their anticipated parenting efficacy levels $t(313)=$ 4.68, $p=.009$; their affinity for children $t(342), p=.000$; and their femininity levels $t(288)=$ 10.16, $p=.014$. When mean substitution was employed, there were no significant gender differences in any of the variables.

As hypothesized and shown in Table 2, the bivariate associations between biological sex and anticipated parenting efficacy $(r=-.09)$, knowledge of developmental milestones $(r==.11)$, contact with children $(r=-.11)$, affinity for children $(r=-.19)$, and femininity levels $(r=-.10)$ were significant. Anticipated parenting efficacy was significantly correlated with contact $(r=$ .10), affinity $(r=.25)$, masculinity $(r=.12)$, and femininity $(r=.25)$. Contrary to prior research findings, knowledge of children's development was not correlated with any of the other variables aside from biological sex. When examining contact with children, it was positively associated with affinity $(r=.40)$, and femininity levels $(r=.12)$. Finally, masculinity and femininity were also negatively correlated within the sample $(r=-.24)$. In summary, participants who liked children more, those who reported more feminine and (to a lesser extent) masculine characteristics, and those who had more contact with children anticipated being more effective parents than those who did not. 


\section{Missingness and Mean Substitution:}

In the current sample, several variables (especially Masculinity and Femininity) had incomplete data, because not all instructors had administered those optional scales to their classes as an in-class activity. In order to correct for this, these data were analyzed with both pairwise deletion of missing values (See Table 3), and with substitution of gendered means for missing data (See Table 2). As correlations on all variables were similar, gendered means were substituted for missing data on all subsequent analyses. The imputation strategy assumes that data points are "missing-completely-at-random" (MCAR), that is, not associated with any IV or DV of interest to the study (Widaman, 2005).

\section{Hypothesis Testing}

A hierarchical regression was used to examine which predictors best accounted for variance in the anticipated parenting efficacy. Based on the findings of Coleman \& Karraker, (2000) and Williams et al. (1987), it was expected that biological sex and contact would be the most predictive contributors to variance in anticipated parenting efficacy. Therefore, they were entered first into the model as Step 1. In order to examine whether knowledge would reduce the effects of sex and contact, knowledge was entered at the second step. Finally, in order to ascertain whether these effects could be better explained by sex roles, masculinity and femininity were entered at the $3^{\text {rd }}$ and final step. Model results are shown in Table 4. Results indicated that the first step of the model, biological sex and contact, accounted for a small yet significant $2 \%$ of the variance in anticipated parenting efficacy scores $(F(2,505)=4.38, p<.05$; $\left.R^{2}=.017\right)$. Only contact emerged as a unique predictor of anticipated parenting efficacy ( $B=$ $.137, p<.05)$. 
At the second step, knowledge about child development was added to the regression equation. The model retained significance, $F(1,504)=2.95, p<.05$. However, knowledge was not a unique predictor of anticipated parenting efficacy $(B=-.024, p=.745)$, and did not explain any additional variance $\left(R^{2}\right.$ change $=.000 ;$ Model $\left.R^{2}=.02\right)$.

To further explain the relation between biological sex and anticipated parenting efficacy, Step Three added masculinity and femininity levels to the regression equation. This model was significant, $F(2,502)=11.18, p<.001$. Together, biological sex, contact, knowledge, masculinity, and femininity, accounted for $10 \%$ of the variance in anticipated parenting efficacy, $\left(R^{2}\right.$ change $\left.=.083, R^{2}=.100\right)$. In the final model, masculinity $(\beta=.046, p<.001)$, and femininity $(b=.068, p<.001)$ were the only variables that uniquely accounted for variance in anticipated parenting efficacy. As evidenced by the change in the standardized regression coefficients from Step 1 to Step 3 (see Table 4) it seems that the influence of biological sex decreases in the presence of other explanatory variables, such as contact, masculinity, and femininity.

\section{Post Hoc Analyses}

Although the hypothesized model was significant, it was expected that the effects of biological sex on parenting efficacy would be more greatly diminished in the presence of masculinity and femininity. Therefore, in order to identify other factors which might explain biological sex's effects on anticipated parenting efficacy, a second hierarchical regression was conducted, in which affinity for children was added to the regressor set. In this model, biological sex was entered alone into Step 1, in order to give this variable the greatest share of variance, as a rigorous test of its predictive value. It was hoped that the effects of sex would 
then be later reduced in significance in subsequent steps of the model. Results of this analysis, shown in Table 5, indicate that biological sex alone accounted for a negligible $1 \%$ of the variance in anticipated parenting efficacy scores $\left(F(1,478)=4.01, p<.05 ;\left(R^{2}=.01\right), 6=-.52\right)$.

Next, knowledge of childhood development, contact with children, and affinity for children were added into the second step of the regression equation. Together, these four variables accounted for $6 \%$ of the variance in anticipated parenting efficacy $(F(4,475)=8.16, p$ $\left.<.001 ; R^{2}=.06\right)$. Step Two uniquely accounted for $6 \%$ of the variance $\left(R^{2} \Delta=.056\right)$. Within Step Two, only affinity for children was a unique predictor of anticipated parenting efficacy $(B=.29)$.

At Step Three, masculinity and femininity were entered into the regression equation. The combined variables of biological sex, knowledge, contact, affinity, femininity, and masculinity were able to account for $14 \%\left(R^{2}=.135\right)$ of the variance in anticipated parenting efficacy, $F(6,473)=12.30, p<.001$, and the variables of masculinity and femininity contributed a unique $7 \%\left(R^{2} \Delta=.071\right)$. In the Final Model, affinity $(B=.242)$, femininity $(B=.065)$, and masculinity $(B=.040)$ were all unique predictors of anticipated parenting efficacy. Biological sex did not emerge as a unique predictor of anticipated parenting efficacy when affinity for children, masculinity, and femininity levels were included in the equation. These results indicate that "biological sex" differences in anticipated parenting efficacy may be the result of a mediating relationship of masculinity and femininity levels, and interpersonal variables such as affinity for children.

Correlations between individual BSRI components and Anticipated Parenting Efficacy Masculinity and femininity are complex constructs that are not easily separated, and may change with societal pressures. In light of this, associations were tested between each 
individual BSRI trait and anticipated parenting efficacy. It was found that the adjectives "yielding," "cheerful," "conscientious," "affectionate," "flatterable," "happy," "feminine," "reliable," "sensitive," "compassionate," "sincere," "understanding," "eager to soothe hurt feelings," “likeable," "masculine," "warm," "solemn," "tender," "friendly," "gullible," "acts as a leader," "does not use harsh language," "loves children," "tactful," “ambitious," and "gentle" were all significantly correlated $(p<.05)$ with anticipated parenting efficacy in a one-way analysis of variance (See Table 6). Although many of these traits are part of the femininity subscale, there are also several traits associated with the masculinity and neutral subscales, suggesting that effective parenting is not directly associated with a particular gender role.

\section{Discussion}

This research of the predictors of anticipated parenting efficacy was guided by Bandura's Self-Efficacy Theory (1989). In accordance with this theory, it was hypothesized that those who had more previous contact with children would report more comfort with becoming a parent themselves. This was consistent with previous research, which has demonstrated a link between contact with children and better parenting practices. Williams (1987) found that mothers with more previous contact with children had children who were more securely attached. Coleman and Karraker (2000) found that mothers with more previous contact with infants and children reported significantly higher levels of both general and task-specific parenting efficacy. The current study replicates these results, with participants who reported higher levels of contact with infants, preschoolers and children scoring higher in anticipated parenting efficacy than those reporting less frequent contact. 
Also in conjunction with Bandura's theory, individuals who report more knowledge of a subject (which is influenced by their contact/experience with the subject) reports higher levels of self-efficacy than less knowledgeable individuals (Bandura, 1989). This too is consistent with previous research in the field, which has demonstrated a link between knowledge of childhood development and parenting efficacy. Conrad et al. (1992) found that the interaction of maternal confidence and knowledge of child development was related to mother-child interactions. Mothers who were more confident and knowledgeable reported more positive interactions with their children. However, the current results did not find a significant association between knowledge of infant and child development and anticipated parenting efficacy. This may be due to problems with the measure used (Field's Developmental Milestones Survey), which had low internal consistency in the current sample. It may be that this measure does not adequately assess participants' knowledge of development, or that a wider range of correct answers should be accepted (for example, $+/-4$ months, rather than the normally accepted $+/-2$ months). Future studies should consider utilizing multiple measures of infant and child knowledge, including those that assess both knowledge of developmental milestones and also knowledge of appropriate parenting practices.

In addition to the research-driven hypotheses regarding contact and knowledge, there were also exploratory analyses conducted to determine the relationship between biological sex and gender roles with anticipated parenting efficacy. Biological sex, masculinity levels, and femininity levels were all significantly correlated with anticipated parenting efficacy. However, it was the aim of this study to attempt to explain the finding that females typically score higher in parenting efficacy than males. In accordance with this aim, a hierarchical regression was 
performed in which biological sex alone was entered as the first step (where it was significant). Next, knowledge of infant development, contact with infants, preschoolers and children, and affinity for children was added into the second step of the regression analysis. With the addition of these variables, biological sex was no longer significant (with the only significant variable being affinity for children). This indicates biological sex differences in anticipated parenting efficacy are better explained by other variables that are correlated with biological sex, such as amount of liking for children. The third step in the hierarchical regression entered masculinity and femininity levels (which were both significant predictors, along with affinity), and reduced the already non-significant beta value of biological sex even further. These results demonstrate the need to look beyond biological sex when exploring differences in parenting skills, and indicate that it is not safe to assume things like child custody of one parent versus the other based solely on that parent's sex.

Individual traits of the BSRI and their association with anticipated parenting efficacy were also examined. Although most of the significantly correlated adjectives were components of the feminine subscale, there were also many masculine and neutral traits, suggesting that the ideal parent is neither strongly masculine nor feminine, but instead more androgynous. Many of the correlated adjectives were reminiscent of traits that are typical of Baumrind's authoritative parenting style, which is often billed as the ideal combination of parenting practices (Baumrind, 1966). Baumrind describes the authoritative parent as one who attempts to guide their children towards decisions while being firm yet supportive, and encouraging independence. They are firm in their decisions, but also lovingly convey their reasoning in a tactful manner (Baumrind, 1966). Adjectives like "acts as a leader," "willing to take a stand," 
and "ambitious" convey this sense of firm guidance, while traits such as "reliable," "sensitive," "compassionate," "sincere," "tender," "tactful," and "gentle" may relate to the qualities of empathy and understanding used to explain decisions and reasoning. The fact that these adjectives correspond to the authoritative parenting style lends support to their being predictors of effective parenting.

\section{Limitations and Future Directions}

Some limitations of this study include its relatively small sample size, and the general homogeneity of its participants. Almost all participants were white and in their early 20s; all were college students This homogeneity may limit the generalizability of the results. However, the age range of the participants can be seen as a unique asset, rather than a limitation. Most of these young adults are about to enter their child-bearing years. According to Erikson, they are at a stage in their life when they are especially open to trying on new roles, such as that of parenting (Erikson, 1959). These factors seem to indicate that this is an ideal age range for research into parenting efficacy, as today's results can be used to instruct tomorrow's parents.

In addition, future studies may also wish to include a measure of general self-efficacy. As self-efficacy is both general and domain-specific (Bandura, 1989), it may be helpful to compare individuals' general self-efficacy levels, to see if those are linked to their anticipated parenting efficacy above and beyond the results of other factors, such as their knowledge or gender roles. It would also be helpful to conduct a longitudinal study of predictive parenting 
factors, to further examine the link between anticipated parenting efficacy and more observational measures of later efficacy when actually a parent.

\section{Conclusions}

In summary, it seems that it is not necessarily women who make more effective parents, but individuals, regardless of sex, who like children, are warm and expressive, but also exhibit healthy controlling behaviors, and a sense of leadership. It is also interesting to note that not only femininity, but also masculinity is necessary to predict high anticipated parenting efficacy. This indicates that good parents are not only nurturing, warm, and "fuzzy," but also exhibit control, leadership, and dominance. The mix of warmth and control shown here seems to indicate further support for the Authoritative parenting style (a balance of the two) being most effective. Future interventions may wish to use the results of this study to identify individuals at risk for low parenting efficacy (such as those with low affinity for children, or low nurturant behaviors), and instruct them in more effective parenting practices. 


\section{References}

Abidin, R. R. (1986). Parenting stress index. Charlottesville, VA: Pediatric Psychology Press.

Adam, E.K., Gunnar, M.R., \& Tanaka, A. (2004). Adult attachment, parent emotion, and observed parenting behavior: Mediator and moderator models. Child Development, $110-122$

Arnett, J.J. (2000). Emerging adulthood: A theory of development from the late teens through the twenties. American Psychologist, 55, 469-480.

Bandura, A. (1989). Human agency in social cognitive theory. American Psychologist, 44, 11751184.

Baumrind, D. (1966). Effects of authoritative parental control on child behavior, Child Development, 37, 887-907.

Bem, S.L. (1974). The measurement of psychological androgyny. Journal of Consulting and Clinical Psychology, 155-162.

Benasich, A. \& Brooks-Gunn, J. (1996). Maternal attitudes and knowledge of child-rearing: Associations with family and child outcomes. Child Development, 67, 1186-1205.

Bondy, E.M., \& Mash, E.J. (1999). Parenting efficacy, perceived control over caregiving failure, and mothers' reactions to preschool children's misbehavior. Child Study Journal, 29, 157-173.

Brems, C. \& Johnson, M.E. (1990). Reexamination of the Bem Sex-Role Inventory: The interpersonal BSRI. Journal of Personality Assessment, 55, 484-498.

Coleman, P.K., \& Karraker, K.H. (2000). Parenting self-efficacy among mothers of school-age children: Conceptualization, measurement, and correlates. Family Relations, 49, 3-24. 
Coleman, P.K., \& Karraker, K.H. (2003). Maternal self-efficacy beliefs, competence in parenting, and toddlers' behavior and developmental status. Infant Mental Health Journal, 126148.

Coleman, P.K., Trent, A., Bryan, S., King, B., Rogers, N., \& Nazir, M. (2002). Parenting behavior, mothers' self-efficacy beliefs, and toddler performance on the Bayley Scales of Infant Development. Early Child Development and Care, 172, 123-140.

Corcoran, K.O. (1998). Deficits in conflict style, attachment, social self-efficacy, and perspective taking of parents seeking parenting skills training. Dissertation Abstracts International: Section B: The Sciences and Engineering, 5188.

Corcoran, K. O. \& Mallinckrodt, B. (2000). Adult attachment, self-efficacy, perspective taking, and conflict resolution. Journal of Counseling \& Development, 473-483.

Erikson, E. H. (1959). Identity and the life cycle: Selected papers. Psychological Issues, 1-171.

Field, T. (1981). Early development of infants born to teenage mothers. In K Scott, T. Field, \& E. Robertson (eds.). Teenage parents and their offspring. Grune and Stratton, New York.

Holt, C.L. \& Ellis, J.B. (1998). Assessing the current validity of the Bem Sex-Role Inventory. Sex Roles, 39, 929-941.

Johnson, J.G., Cohen, P., Chen, H., Kasen, S., Brook, J.S. (2006). Parenting behaviors associated with risk for offspring personality disorder during adulthood. Arch Gen Psychiatry, 63, 579-587.

Johnston, C. \& Mash, E.J. (1989). A measure of parenting satisfaction and efficacy. Journal of Clinical Child Psychology, 18, 167-175. 
Karraker, K.H. \& Evans, S.L. (1996). Adolescent mothers' knowledge of child development and expectations for their own infants. Journal of Youth and Adolescence, 25, 651-666.

Larsen, J. \& McCreary Juhasz, A. (1985). The effects of knowledge of child development and social-emotional maturity on adolescent attitudes toward parenting. Adolescence, 20, 823-839.

Maznah, I. \& Choo, P.F. (1986). The factor structure of the Bem Sex-Role Inventory (BSRI). International Journal of Psychology, 21, 31-41.

Raver, C.C., \& Leadbeater, B.J. (1999). Mothering under pressure: Environment, child, and dyadic correlates of maternal self-efficacy among low-income women. Journal of Family Psychology, 523-534.

Schilmoeller, G.L. \& Baranowski, M.D. (1985). Childrearing of firstborns by adolescent and older mothers. Adolescence, 20, 805-822.

Shumow, L. \& Lomax. R. (2002). Parental efficacy: Predictor of parenting behavior and adolescent outcomes. Parenting Science and Practice, 2, 127-150.

Tabachnick, B.G. \& Fidell, L.S. (2007). Using Multivariate Statistics ( $5^{\text {th }}$ ed.). Boston: Pearson Education, Inc.

Teti, D. M. \& Gelfand, D. M. (1991). Behavioral competence among mothers of infants in the first year: The mediational role of maternal self-efficacy. Child Development, 62, 918929.

Twentyman, C.T. \& Plotkin, R.C. (1982). Unrealistic expectations of parents who maltreat their children: An educational deficit that pertains to child development. Journal of Clinical Psychology, 38, 497-503. 
U.S. Department of Health and Human Services. (2006). Child maltreatment 2005. Washington, DC: Government Printing Office. Retrieved October 23, 2006, from http://www.acf.hhs.gov/programs/cb/pubs/cm04/cm04.pdf

Widaman, K. F. (2005). Missing data: What to do with or without them. In Monographs of the Society for Research in Child Development, 71 (3, Serial No. 285).

Williams, T.M., Joy, L.A., Travis, L., Gotowiec, A., Blum-Steele, M., Aiken, L.S., Painter, S.L., \& Davidson, S.M. (1987). Transition to motherhood: A longitudinal study. Infant Mental Health Journal, 251-265. 
Table 1

Mean gender differences in dependent variables: means, t-tests, and significance levels.

\begin{tabular}{|lllll|}
\hline Variable & Male $(\mathrm{M})$ & Female $(\mathrm{M})$ & $t(\mathrm{df})$ & $p$ \\
\hline Anticipated Parenting Efficacy & 32.51 & 34.30 & $4.68(313)$ & .009 \\
Anticipated P.E. (mean replace) & 33.20 & 33.71 & $2.01(479)$ & .382 \\
Knowledge & 3.99 & 4.50 & $2.76(414)$ & .557 \\
Knowledge (mean replacement) & 4.06 & 4.43 & $2.32(479)$ & .551 \\
Contact & 8.19 & 9.06 & $3.67(349)$ & .472 \\
Contact (mean replacement) & 8.38 & 8.81 & $2.35(479)$ & .171 \\
Affinity & 10.13 & 12.11 & $7.39(342)$ & .000 \\
Affinity (mean replacement) & 10.63 & 11.51 & $4.16(479)$ & .871 \\
Masculinity & 103.46 & 93.34 & $-6.18(288)$ & .356 \\
Masculinity (mean & 98.65 & 96.96 & $-1.59(479)$ & .131 \\
replacement) & & & & \\
Femininity & 89.04 & 103.05 & $10.16(288)$ & .014 \\
Femininity (mean replacement) & 95.70 & 98.07 & $2.29(478)$ & .238 \\
\hline
\end{tabular}


Table 2

Means, Standard Deviations, and Correlations, with mean substitution for missing values.

\begin{tabular}{|lcccccccccc|}
\hline \multicolumn{1}{c}{ Variable } & 1 & 2 & 3 & 4 & 5 & 6 & 7 & Mean & SD & N \\
\hline 1. Biological Sex & -- & $-.09^{*}$ & $-.11^{*}$ & $-.11^{*}$ & $-.19^{* *}$ & .07 & $-.10^{*}$ & 1.34 & 0.47 & 481 \\
2. Anticipated Parental & & -- & -.004 & $.10^{*}$ & $.25^{* *}$ & $.12^{* *}$ & $.25^{* *}$ & 33.54 & 2.71 & 485 \\
Efficacy & & & & & & & & & \\
3. Knowledge & & & -- & .02 & .08 & -.03 & .03 & 4.31 & 1.66 & 487 \\
4. Contact & & & & -- & $.40^{* *}$ & .04 & $.12^{* *}$ & 8.66 & 1.87 & 481 \\
5. Affinity & & & & & -- & $.12^{* *}$ & $.12^{*}$ & 11.22 & 2.23 & 481 \\
6. Masculinity & & & & & & -- & $-.24^{* *}$ & 97.51 & 10.97 & 486 \\
7. Femininity & & & & & & & -- & 97.33 & 10.87 & 485 \\
\hline
\end{tabular}

Note. ${ }^{*} p<.05 . * * p<.01 . * * * p<.001$ 
Table 3

Means, Standard Deviations, and Correlations, with pairwise deletion of missing values.

\begin{tabular}{|c|c|c|c|c|c|c|c|c|c|c|}
\hline Variable & 1 & 2 & 3 & 4 & 5 & 6 & 7 & Mean & SD & $\mathrm{N}$ \\
\hline 1. Biological Sex & -- & $-.26 * *$ & $-.14 * *$ & $-.19 * *$ & $-.37 * *$ & $.34 * *$ & $-.51 * *$ & 1.34 & 0.47 & 481 \\
\hline $\begin{array}{l}\text { 2. Anticipated Parental } \\
\text { Efficacy }\end{array}$ & & -- & .01 & $.21 * *$ & $.52 * *$ & $.15^{*}$ & $.52 * *$ & 33.73 & 3.26 & 319 \\
\hline 3. Knowledge & & & -- & .04 & $.13^{*}$ & -.08 & -.10 & 4.33 & 1.78 & 422 \\
\hline 4. Contact & & & & -- & $.38 * *$ & .01 & $.31 * *$ & 8.75 & 2.17 & 351 \\
\hline 5. Affinity & & & & & -- & .03 & $.50 * *$ & 11.41 & 2.54 & 344 \\
\hline 6. Masculinity & & & & & & -- & $-.12 *$ & 96.30 & 13.38 & 295 \\
\hline 7. Femininity & & & & & & & -- & 99.01 & 12.52 & 295 \\
\hline
\end{tabular}

Note. ${ }^{*} p<.05 . * * p<.01 . * * * p<.001$ 
Table 4

A Hierarchical Multiple Regression Analysis Predicting Anticipated Parenting Efficacy, with mean substitutions.

\begin{tabular}{|c|c|c|c|c|c|}
\hline Variable & $\beta$ & $S E B$ & $b$ & $F$ & $R^{2}$ \\
\hline \multicolumn{6}{|l|}{ Step 1} \\
\hline Biological Sex & -.46 & .26 & -.08 & $4.38^{*}$ & .02 \\
\hline Contact & $.14^{*}$ & .06 & .10 & & \\
\hline \multicolumn{6}{|l|}{ Step 2} \\
\hline Biological Sex & -.08 & .26 & -.08 & $2.95^{*}$ & .02 \\
\hline Contact & $.14^{*}$ & .07 & .10 & & \\
\hline Knowledge & -.02 & .07 & -.01 & & \\
\hline \multicolumn{6}{|l|}{ Step 3} \\
\hline Biological Sex & -.41 & .25 & -.07 & $11.18^{* * *}$ & .10 \\
\hline Contact & .08 & .06 & .06 & & \\
\hline Knowledge & -.03 & .07 & -.02 & & \\
\hline Masculinity & $.05 * * *$ & .01 & .19 & & \\
\hline Femininity & $.07 * * *$ & .01 & .27 & & \\
\hline
\end{tabular}

Note. ${ }^{*} p<.05 .{ }^{* *} p<.01 .{ }^{* * *} p<.001, \mathrm{~N}=481$. 


\section{Table 5}

Post-hoc Analysis Predicting Anticipated Parenting Efficacy, with mean substitutions.

\begin{tabular}{|c|c|c|c|c|c|}
\hline Variable & $\beta$ & $S E B$ & $b$ & $F$ & $R^{2}$ \\
\hline \multicolumn{6}{|l|}{ Step 1} \\
\hline Gender & $-.52 *$ & .26 & -.09 & $4.01 *$ & .01 \\
\hline \multicolumn{6}{|l|}{ Step 2} \\
\hline Gender & -.28 & .26 & -.05 & $8.16 * * *$ & .06 \\
\hline Knowledge & -.05 & .07 & -.03 & & \\
\hline Contact & .00 & .07 & .00 & & \\
\hline Affinity & $.29 * * *$ & .06 & .24 & & \\
\hline \multicolumn{6}{|l|}{ Step 3} \\
\hline Gender & -.25 & .25 & -.04 & $12.30 * * *$ & .14 \\
\hline Knowledge & -.05 & .07 & -.03 & & \\
\hline Contact & -.03 & .07 & -.02 & & \\
\hline Affinity & $.24 * * *$ & .06 & .20 & & \\
\hline Femininity & $.07 * * *$ & .01 & .26 & & \\
\hline Masculinity & $.04 * * *$ & .01 & .16 & & \\
\hline
\end{tabular}

Note. ${ }^{*} p<.05,{ }^{* *} p<.01, * * * p<.001, \mathrm{~N}=481$ 
Table 6

Analysis of variance for Anticipated Parenting Efficacy scores

\begin{tabular}{|lllll|}
\hline Source & $d f$ & $M S$ & $F$ & $p$ \\
\hline Yielding & 18 & 2.46 & 1.93 & .014 \\
Cheerful & 18 & 1.74 & 1.76 & .030 \\
Conscientious & 18 & 2.52 & 1.85 & .020 \\
Affectionate & 18 & 3.52 & 2.94 & .000 \\
Flatterable & 18 & 2.55 & 1.63 & .054 \\
Happy & 18 & 1.29 & 1.51 & .084 \\
Feminine & 18 & 22.66 & 6.97 & .000 \\
Reliable & 18 & 2.03 & 2.79 & .000 \\
Sensitive to others' needs & 18 & 4.24 & 4.51 & .000 \\
Compassionate & 18 & 1.98 & 2.30 & .004 \\
Sincere & 18 & 1.15 & 1.71 & .034 \\
Understanding & 18 & 1.72 & 2.24 & .003 \\
Eager to soothe hurt feelings & 18 & 3.47 & 2.43 & .001 \\
Likeable & 18 & 1.57 & 2.59 & .001 \\
Masculine & 18 & 20.71 & 6.02 & .000 \\
Warm & 18 & 2.70 & 2.63 & .000 \\
Solemn & 18 & 2.74 & 1.66 & .047 \\
Willing to take a stand & 18 & 2.27 & 1.62 & .055 \\
Tender & 18 & 4.65 & 3.79 & .000 \\
Friendly & 18 & 1.68 & 2.16 & .005 \\
Gullible & 18 & 4.44 & 1.70 & .040 \\
Acts as a leader & 18 & 3.41 & 1.98 & .011 \\
Does not use harsh language & 18 & 7.36 & 2.66 & .000 \\
Loves Children & 18 & 8.26 & 5.15 & .000 \\
Tactful & 18 & 3.13 & 2.19 & .004 \\
Ambitious & 18 & 2.08 & 1.91 & .015 \\
Gentle & 18 & 4.51 & 4.29 & .000 \\
\hline
\end{tabular}

Note: Only sources for which $p<.05$ are included in this table. 
Appendix

Developmental Milestones Survey:

Developmental Milestones Survey: Age (specify whether that is in days, weeks, months, or years)

a. At what age do you think a baby should first smile? (4 weeks)

b. At what age should a baby be able to crawl? (32 weeks)

c. At what age do you think babies should be able to first sit alone without support?

(32 weeks)

d. At what age do you think a baby should be able to pull himself or herself up by using furniture?

(40 weeks)

e. At what age do you think a baby should be able to take his or her first steps without help?

(52 weeks)

f. At what age do you think a baby should be able to say his or her first real words (i.e., something other than "mama")?

(52 weeks)

g. At what age do you think a baby should be potty trained so that the baby doesn't need diapers?

(2 years)

h. At what age do you think a baby should begin to obey when told "no"?

(2 years) 


\section{Experience Measures}

During the past year, on average, how frequently have you had contact with:
a. Infants
b. Preschoolers
c. Young children

Response Scale: (At least once a week, At least once a month, Rarely (less than 1 time/month), Not at all) 


\section{Affinity Measures}

How much do you like:
a. Infants
b. Preschoolers
c. Young children

Response scale: (Much more than average, More than average, Average, Less than average, Much less than average) 
BSRI

Please rate yourself on each of the following items using the following scale:

1

Never Usually

Never

True

( $M=$ Masculine trait
3

Sometimes

but Infrequently

Not True

$$
4
$$

Occasionally

True

$F=$ Feminine trait
5

6

Usually

True

True

True

$N=$ Neutral trait)
7

Always

or

Almost

Always

True

\begin{tabular}{|c|c|}
\hline M & 1. Self-reliant \\
\hline $\mathrm{F}$ & 2. Yielding \\
\hline $\mathrm{N}$ & 3. Helpful \\
\hline M & 4. Defends own beliefs \\
\hline $\mathrm{F}$ & 5. Cheerful \\
\hline $\mathrm{N}$ & 6. Moody \\
\hline $\mathrm{M}$ & 7. Independent \\
\hline $\mathrm{F}$ & 8. Shy \\
\hline $\mathrm{N}$ & 9. Conscientious \\
\hline M & 10. Athletic \\
\hline $\mathrm{F}$ & 11. Affectionate \\
\hline $\mathrm{N}$ & 12. Theatrical \\
\hline $\mathrm{M}$ & 13. Assertive \\
\hline $\mathrm{F}$ & 14. Flatterable \\
\hline $\mathrm{N}$ & 15. Нарру \\
\hline M & 16. Strong Personality \\
\hline $\mathrm{F}$ & 17. Loyal \\
\hline $\mathrm{N}$ & 18. Unpredictable \\
\hline M & 19. Forceful \\
\hline $\mathrm{F}$ & 20. Feminine \\
\hline $\mathrm{N}$ & 21. Reliable \\
\hline M & 22. Analytical \\
\hline $\mathrm{F}$ & 23. Sympathetic \\
\hline $\mathrm{N}$ & 24. Jealous \\
\hline$M$ & 25. Leadership ability \\
\hline $\mathrm{F}$ & 26. Sensitive to others' needs \\
\hline $\mathrm{N}$ & 27. Truthful \\
\hline M & 28. Willing to take risks \\
\hline $\mathrm{F}$ & 29. Understanding \\
\hline $\mathrm{N}$ & 30. Secretive \\
\hline
\end{tabular}

M 31. Makes decisions easily

F 32. Compassionate

$\mathrm{N}$ 33. Sincere

M 34. Self-reliant

$\mathrm{F}$ 35. Eager to soothe hurt feelings

$\mathrm{N}$ 36. Conceited

M 37. Dominant

$\mathrm{F}$ 38. Soft-spoken

$\mathrm{N}$ 39. Likable

M 40. Masculine

F 41. Warm

$\mathrm{N}$ 42. Solemn

$M$ 43. Willing to take a stand

$\mathrm{F}$ 44. Tender

$\mathrm{N}$ 45. Friendly

$M$ 46. Aggressive

$\mathrm{F}$ 47. Gullible

$\mathrm{N}$ 48. Inefficient

M 49. Acts as a leader

$\mathrm{F}$ 50. Childlike

$\mathrm{N}$ 51. Adaptable

M 52. Individualistic

$\mathrm{F}$ 53. Does not use harsh language

$\mathrm{N}$ 54. Unsystematic

M 55. Competitive

$\mathrm{F}$ 56. Loves children

$\mathrm{N}$ 57. Tactful

$M$ 58. Ambitious

$\mathrm{F}$ 59. Gentle

$\mathrm{N}$ 60. Conventional 


\section{Maternal Efficacy Questionnaire}

Response scale: (Not good at all, Not good enough, Good enough, Very good)

1. When your baby is upset, fussy or crying, how good do you think you will be at soothing him or her?

2. How good do you think you will be at understanding what your baby needs or wants? For example, how well do you think you will know when your baby needs to be changed or wants to be fed?

3. How good do you think you will be at making your baby understand what you want him or her to do? For example, if you want your baby to eat dinner or play quietly, how good will you be at making him or her do that?

4. How good do you think you will be at getting your baby to pay attention to you? For example, when you want your baby to look at you, how good will you be at making him or her do it?

5. How good do you think you will be at getting your baby to have fun with you? For example, how good do you think you will be at getting your baby to smile and laugh with you?

6. How good do you think you will be at knowing what activities your baby will enjoy? For example, how good will you be at knowing what games and toys your baby will like to play with? 
7. How good will you be at keeping your baby occupied when you need to do some work around the house? For example, how good will you be at finding things for the baby to do when you need to do the dishes or fix something?

8. How good do you feel you will be at feeding, changing, and bathing your baby?

9. How good do you think you will be at getting your baby to show off for visitors? For example, how good do you think you will be at making your baby smile or laugh for people who visit?

10. In general, how good a parent of an infant do you think you will be? 
Date: April, 2009

\title{
Vita
}

\section{Danielle Tomczewski}

\author{
1604 Brunswick Court \\ Morgantown, WV 26508 \\ (304) 282-0404 \\ DTomczewski@gmail.com
}

\section{PERSONAL INFORMATION:}

Birth Date: June 8, 1983

Citizenship: USA

Birth Place: West Virginia

\section{EDUCATION:}

M.S., Lifespan Developmental Psychology

West Virginia University, Morgantown, WV

May, 2009.

B.A., Psychology, 2005, West Virginia University, Morgantown, WV

Minors in Communications and English

GPA: 3.91, Graduated summa cum laude.

\section{HONORS AND AWARDS:}

- Certificate of Achievement for Academic Excellence. Awarded by the Eberly College of Arts and Sciences of West Virginia University, 2004, 2005.

- Presidential Award for Excellence in Scholarship: In recognition of earning a perfect 4.0 Grade Point Average. Awarded by West Virginia University, Fall 2002, Fall 2003, Spring 2004, Fall 2004, Spring 2005.

- Top of the Mountain Award: Academic Excellence in the Mountain State Certificate of Recognition. Awarded by the State of West Virginia, 2001.

\section{PROFESSIONAL \& HONOR SOCIETIES:}

- Student Affiliate of American Psychological Association

- Student Affiliate of Gerontological Society of America

- Golden Key International Honor Society 
- Phi Beta Kappa International Honor Society

\section{RESEARCH INTERESTS:}

My research interests involve parenting efficacy across the lifespan. My M.S. thesis examined the predictors of anticipated parenting efficacy in younger adults. Other research projects have included the areas of teenage pregnancy, and parenting efficacy in middle age and older adulthood, through custodial grandparenting. My general area of focus is the middle aged and older adult population, and areas where men are the under-represented population.

\section{CURRENT RESEARCH:}

This semester I have been replicating the results of my master's thesis using multiple and improved measures, with a larger sample size. I have also been supervising 11 undergraduate research assistants working on a lab project which seeks to validate computerized cognitive interventions against accepted measures.

\section{TEACHING EXPERIENCE:}

Fall $2004 \quad$ Teaching assistant Psychology as a Profession

- prepared in-class activities and supplemental materials

- designed and created a large bulletin board on the topic of graduate school

- assisted students with their assignments

- helped the GTA to input grades

Fall 2005 Graduate Teaching Assistant Introduction to Psychology

- enhanced provided powerpoint lectures

- taught the material to my students

- conducted and recorded in-class activities

- developed study materials

- served in the Testing and Learning Center during students' computerized quizzes

- was available in and out of class to answer students' questions

Fall 2006 - Spring 2007 Graduate Teaching Assistant Psychology as a Profession

- was responsible for developing and presenting several lectures each semester

- graded students' activity papers and quizzes weekly

- recruited and scheduled guest lecturers

- held office hours weekly

- developed comprehensive optional final exams

- assisted Dr. Chase in the maintenance of the course over the semesters

Fall 2007 - Spring 2008 Graduate Teaching Assistant Psych. of Human Development

- held responsibilities similar to those of Psychology 101, including enhancing and presenting lectures, holding office hours, and developing reviews and study guides.

Summer 2008 - Current Pre-Psychology Advisor \& Sona Systems Administrator 
- Serve as the primary advisor for all pre-psychology undergraduate students who have completed at least 29 credit hours. Duties include providing students with all requirements they have left for graduation, a recommended schedule for the remainder of their time at the university, term pins, and information regarding minors, careers, graduate school, and other general questions.

- As a Sona systems administrator, I monitor the use of our online survey and scheduling system, provide instructors with their students' extra credit points, approve online studies, and answer all questions related to use of or problems with the system.

\section{CONFERENCES ATTENDED:}

September, 2006 West Virginia Psychologial Assoc. Davis, WV

November, 2006 Gerontological Society of America. Dallas, TX.

November, 2007 Gerontological Society of America. San Francisco, CA

November, 2008 Gerontological Society of America. Washington D.C.

\section{POSTERS AT PROFESSIONAL MEETINGS:}

Tomczewski, D.K. \& Patrick, J.H. (2005). Older Men: Thriving in West Virginia. Poster presented at the annual Eberly College of Arts and Sciences Research Poster Day. Morgantown, WV.

Patrick, J.H. \& Tomczewski, D.K. (2006). Everyday decisions: Age and experience effects in decision quality. Poster presented at the annual meeting of the Gerontological Society of America. Dallas, TX.

Tomczewski, D.K. \& Patrick, J.H. (2006). Older men: Thriving in West Virginia. Poster presented at the annual meeting of the West Virginia Psychological Association. Davis, WV.

Tomczewski, D.K. \& Patrick, J.H. (2007). Understanding Civic Engagement Behaviors Among Young Adults. Poster presented at the annual Eberly College of Arts and Sciences Research Poster Day. Morgantown, WV.

\section{PRESENTATIONS AT PROFESSIONAL MEETINGS:}

Tomczewski, D.K. \& Patrick, J.H. (2007). Custodial grandfathers: The new hidden caregiver? Opening summary to a symposium at the annual Gerontological Society of America meeting. San Fransisco, CA.

Patrick, J.H., Tomczewski, D.K., \& Hayslip, B. (2008). Personal experience and attitudes towards custodial grandparenting. Paper presented as part of symposium at the annual Gerontological Society of America meeting. Washington, D.C. 


\section{MANUSCRIPTS:}

Patrick, J.H. \& Tomczewski, D.K. (2007). Custodial grandfathers. Journal of Intergenerational Relationships, 5.4. 